I Fundação Oswaldo Cruz (Fiocruz), Casa de Oswaldo Cruz, Rio de Janeiro, RJ, Brasil nisia.lima@fiocruz.br

II Fundação Oswaldo Cruz (Fiocruz), Casa de Oswaldo Cruz, Rio de Janeiro, RJ, Brasil racheldeaviana@gmail.com

\author{
Nísia Trindade Lima' \\ Rachel de Almeida Viana"
}

\title{
ENTRE LATIFÚNDIOS E FAVELAS: O BRASIL URBANO NO PENSAMENTO DE ANTHONY LEEDS
}

\begin{abstract}
O problema tratado no nosso trabalho é, na verdade, parte de um muito maior, a compreensão da sociedade total no Brasil. Meu primeiro campo de estudo foi uma plantation, área de latifúndio da zona monocultora no sul da Bahia; o segundo estudo envolveu o trabalho em uma série de cidades, o estudo de elites, e o terceiro foi nas áreas da classe trabalhadora urbana. Em outras palavras, trabalhei em vários setores da sociedade tentando obter diferentes perspectivas de toda a estrutura institucional, escolhendo vários pontos do sistema em sua totalidade (Leeds \& Leeds, 2015: I76-177).
\end{abstract}

Em texto escrito originalmente em I970 e que utilizamos como epígrafe a este artigo, Anthony Leeds apresentava como objetivo de parte expressiva de sua produção intelectual a tentativa de desenvolver uma explicação de natureza geral sobre a sociedade brasileira. Realizados em períodos distintos de sua carreira - de jovem doutorando da Universidade de Columbia a chefe de estudos urbanos da União Pan-Americana, consultor internacional dos Peace Corps Volunteers ${ }^{1}$ e professor da Universidade do Texas - seus trabalhos mais conhecidos entre nós são os referidos às pesquisas em favelas, em grande parte como resultado da publicação, em I978, em coautoria com Elizabeth Leeds, de A sociologia do Brasil urbano. ${ }^{2}$

Obra de referência para os estudos urbanos no país, o livro reúne textos sobre as relações entre estrutura social, com ênfase no mercado de trabalho, e recursos de poder formais e informais na sociedade brasileira, atribuindo centralidade ao espaço urbano. Demonstra ainda a tentativa de formular modelos explicativos para processos de mudança social a partir de uma proposta de tipologia da evolução das sociedades. Nesse livro e na autobiografia que deixou inconclusa, Anthony Leeds apresentava seu esforço teórico como tributário do 
marxismo, mas também de uma combinação de perspectivas, com destaque para a teoria dos sistemas e a análise ecológica (Leeds, I984). Não se via como antropólogo urbano, mas como um analista das sociedades concebidas como sistemas totais para cuja análise não caberia a separação entre sociologia/antropologia urbana e sociologia/antropologia rural.

Anthony Leeds esteve dedicado a diferentes temas e, durante os anos de 1950 a I970, período delimitado neste artigo, preocupou-se com a formulação de modelos explicativos para processos de mudança social e com o desenvolvimento de uma concepção própria do marxismo e da teoria de classes sociais (Leeds, I984, Sanjek, I994). Esteve dedicado ao que Sanjek denominou antropologia ecológica e materialista, interessado particularmente em "instrumentos, solos, cultivos e animais" (Sanjek, I 994: 27) e, podemos acrescentar, em atividades econômicas as mais diversas realizadas em localidades como as favelas do Rio de Janeiro. Não obstantes a relevância dos estudos no Brasil e seu papel no primeiro curso de antropologia urbana, oferecido em I969 pelo recém-criado Programa de Antropologia Social do Museu Nacional, e na formação de cientistas sociais brasileiros e norte-americanos na prática de pesquisa, faltam obras sistemáticas sobre sua contribuição, denotando, em parte, uma lacuna nas análises sobre pensamento social no Brasil referente à emergência dos estudos urbanos nos anos i950 e ig60.

Sobre a contribuição de Anthony Leeds às ciências sociais, destacam-se, entre as obras brasileiras, a dissertação de Rachel de A. Viana (20I4) sobre a trajetória intelectual de Anthony Leeds e sua pesquisa sobre as favelas do Rio de Janeiro; o livro A invenção da favela, de Licia Valladares (2005), no qual a autora ressalta a relevância das pesquisas realizadas por Anthony e Elizabeth Leeds no desenvolvimento inicial de estudos sociológicos sobre essas localidades; o artigo de Gilberto Velho (20 I I) sobre antropologia urbana e fronteiras do conhecimento, e o de Luiz Antonio Machado da Silva (20I5) sobre a importância do antropólogo na formação acadêmica e de ética de pesquisa de um grupo de jovens brasileiros e norte-americanos que com ele iniciou seus estudos sobre as favelas. Para Silva (20I5), Anthony Leeds teria sido sobretudo uma referência de como realizar pesquisa empírica e um modelo de intelectual, sem pedestal, aberto à crítica e ao diálogo com todos os seus interlocutores.

Nos Estados Unidos, a análise da contribuição do autor também não corresponde à abrangência e relevância de seus trabalhos. O livro Cities, classes and social order (Leeds, I994), editado por Roger Sanjek, que nele compila artigos de Anthony Leeds, inclui um texto do próprio Sanjek e outro de Timothy Sieber (I994), sobre a contribuição antropológica e sobre a biografia e trajetória intelectual do autor, respectivamente. Os contextos latino americanos são pouco analisados, e não se incluiu na coletânea o estudo sobre carreiras brasileiras e estrutura social (Leeds, 20 I 5 [I962]), ${ }^{3}$ considerado por Leeds texto de referência para a análise da sociedade brasileira e as pesquisas posteriores nas favelas 
cariocas. Publicado originalmente em I964, o trabalho em questão integra A sociologia do Brasil urbano (Leeds \& Leeds, 20I5).

Neste artigo pretendemos analisar a contribuição do autor, considerando os trabalhos realizados no Brasil, com destaque para o estudo sobre favelas. Com essa perspectiva, acentuamos sua análise sobre a visão dos moradores dessas localidades e respectivas estratégias cotidianas, ao mesmo tempo em que discutimos o fenômeno por ele denominado mito da ruralidade. Ainda que não seja nosso objetivo uma comparação sistemática entre as diferentes pesquisas que o autor empreendeu sobre o Brasil, estabeleceremos alguns elementos de comparação entre sua tese de doutoramento sobre a zona do cacau, o estudo de carreiras e a análise sobre favelas.

Em nosso entendimento o estudo da obra de Anthony Leeds a respeito da sociedade brasileira permite ampliar a compreensão das ciências sociais produzidas por antropólogos norte-americanos sobre o Brasil e a América Latina durante as décadas de I950 a I970, colocando em relevo perspectivas críticas ao pensamento hegemônico norte-americano orientado por teorias como a da modernização ${ }^{4}$ e pelo recurso metodológico aos estudos de comunidade. Ao mesmo tempo, pretendemos chamar atenção para o diálogo intelectual e contribuições de estudos de intelectuais brasileiros, especialmente de Anísio Teixeira, em suas pesquisas.

Nossa hipótese é que o estudo das favelas do Rio de Janeiro permitiu maior refinamento dos argumentos de Leeds sobre a organização social do Brasil. Mais do que localidades onde residiam pobres urbanos - chave explicativa que dominava, nos anos I950 e I960, os ainda incipientes estudos sociológicos sobre favelas -, elas foram vistas por Leeds como estruturas dinâmicas de circulação de pessoas e capitais, expressando as estratégias de negociação e poder dos trabalhadores urbanos para lidar com as contradições de uma sociedade que vivia um acelerado processo de urbanização. Ele pôs em foco as estratégias múltiplas dos trabalhadores urbanos, entre elas, a opção pela moradia em favelas como expressão de sua capacidade de agência diante das características de desigualdade social e institucionalização da pobreza na sociedade brasileira.

\section{PADRÃO CULTURAL NOS LATIFÚNDIOS DA ZONA DO CACAU}

Jovem estudante de graduação e posteriormente de pós-graduação na Universidade de Columbia entre I947 e I957, Anthony Leeds viveu intensamente o clima intelectual e político do pós-Segunda Guerra Mundial e início da Guerra Fria. Em Columbia, participou de dois grupos de estudo sobre marxismo e ao longo de sua carreira definiu-se como antropólogo fortemente influenciado por essa corrente de pensamento, ainda que recusasse o que denominava marxis mo ideológico e buscasse desenvolvimento teórico mais amplo sobre as relações de poder, evitando subsumi-las em uma análise esquemática das classes sociais 
(Leeds, 2015 [I978]: 5I-52). Os anos do pós-guerra foram também marcados por forte orientação no sentido de promover mudança social e desenvolvimento por meio da cooperação internacional entre os Estados Unidos da América do Norte e os países latino-americanos, política declarada, em I949, no Ponto IV do programa de Harry Truman à presidência daquele país. ${ }^{5} \mathrm{~A}$ chamada política de boa vizinhança teria criado as condições para o desenvolvimento de uma antropologia da boa vizinhança (Figueiredo, 2009). Desnecessário afirmar que seria incorreto, contudo, inferir desse enquadramento político a natureza e as contribuições dos diferentes estudos antropológicos realizados, uma vez que o dissenso na academia norte-americana era expressivo, do que, aliás, são exemplares a atuação de Leeds e a perspectiva crítica adotada em seus trabalhos.

De todo modo, foi esse o contexto no qual se firmou o convênio entre o estado da Bahia e a Universidade de Columbia, resultado em grande medida dos esforços do então secretário de Saúde e Educação da Bahia, Anísio Teixeira, contando também com o apoio financeiro do Viking Fund, do Social Science Research Council e da Doherty Foundation (Wagley, Azevedo \& Pinto, I950). O projeto de pesquisa, mais conhecido como Bahia-Columbia, contou com estudantes de pós-graduação, que, a partir dele, realizaram suas teses de doutoramento, e foi dirigido por Charles Wagley, Thales de Azevedo, então diretor da Fundação para o Desenvolvimento da Ciência no Estado da Bahia, e Luiz de Aguiar da Costa Pinto, caracterizando-se pelo estudo do tradicional e do moderno e pela comparação entre duas comunidades em cada lugar (Consorte, I999). Foi motivado pelo interesse no desenvolvimento econômico e social e examinou as perspectivas de mudança social e a inserção de novas tecnologias nas produções locais.

As comunidades estudadas foram escolhidas por Thales de Azevedo, Costa Pinto e Eduardo Galvão, que adotaram como principal critério a relevância econômica para a região (Consorte, I999; Consorte \& Pereira, 20Io; Maio, I997). A definição de comunidade expressava a perspectiva de Charles Wagley para o estudo das chamadas sociedades de folk, segundo uma matriz de análise que fora inicialmente utilizada em pesquisas sobre comunidades rurais nos Estados Unidos e que teve como um dos principais autores Robert Redfield. Além da região do cacau no sul do estado, a cargo de Anthony Leeds, foram estudadas por Benjamin Zimmerman as regiões do gado no Nordeste do estado; por Harry Hutchinson a do açúcar, localizada no Recôncavo Baiano; e, por Marvin Harris, a das lavras, situada na Chapada Diamantina ${ }^{6}$ (Wagley, Azevedo \& Costa Pinto, I950: I6-18).

A tese Economic Cycles in Brazil: the persistence of a total culture pattern: cacao and other cases, 7 orientada por Charles Wagley, resultou do trabalho de campo realizado por Leeds de junho de I95 I a agosto de I952, após a conclusão dos trabalhos de campo dos estudantes que pesquisaram outras áreas. Esse fato favoreceu a adoção de uma perspectiva comparada, uma das mais fortes 
características dos estudos antropológicos de Anthony Leeds. Desse modo, a hipótese dos ciclos econômicos foi aferida para a produção de cacau, mas também em relação às produções de borracha, café e açúcar, utilizando os estudos de comunidade empreendidos por seus colegas do projeto Bahia-Columbia e de outros projetos para traçar essas comparações. ${ }^{8}$

Esse ponto indica uma diferença com relação aos outros estudos de comunidade realizados sob orientação de Wagley. Uma das características importantes no trabalho foi articular diferentes níveis de análise, com ênfase no que Leeds denominava questões supralocais, o que incluía o nível internacional, especialmente o mercado do cacau, o nível nacional, com destaque para o financiamento por intermédio de agências como o Banco do Brasil, e aspectos locais da produção do cacau. Outro ponto importante refere-se ao recurso à comparação com as pesquisas realizadas por seus colegas de Columbia. Esta orientação de pesquisa, no sentido de privilegiar comparações com outros es tudos, caracteriza toda a produção intelectual de Leeds que nunca publicou uma etnografia de localidade específica.

Em sua autobiografia, ele observa as tensões entre sua concepção, segundo a qual a descrição da pequena cidade em que fixara residência seria irrelevante, e a exigência de incluir tal descrição em conformidade ao padrão dos estudos de comunidade. Segundo o autor:

No rascunho da tese não inseri minha localidade de residência, uma vez que, per se, ela esclarecia pouco acerca das estruturas e dos processos que eu estava descrevendo. Sob pressão, a versão final continha umas poucas páginas, obedientes e desnecessárias, sobre a cidade em que vivi - eram um reflexo do "estudo de comunidade" que então dominava o campo (Leeds, I984: 55).

Ao mesmo tempo, Leeds acentua as ligações econômicas e administrativas entre a cidade e as fazendas do entorno, elo cujos aspectos centrais seriam o mercado, a posse e o uso da terra. Ele parte da hipótese de que uma área comandada por uma cidade depende da produtividade de terras que a circundam. Logo, a estrutura de uma cidade deveria ser entendida em relação à estrutura econômica e administrativa das fazendas do entorno, pois a interdependência entre as fazendas, e destas com a cidade, se daria por vários elementos: transportes, mercado, fornecimento de bens, posse de terra e eventos religiosos. As conexões se dariam também pelas relações familiares e práticas de sociabilidade como visitas, casamentos, parentesco e conversas informais. ${ }^{9}$

O fator central, que contraria a ideia de isolamento e reforça a de integração entre as localidades, seria a dinâmica da monocultura do cacau. A dependência do mercado externo imporia uma adaptação dos produtores a essa dinâmica, bem como uma adaptação interna de natureza tecnológica, socioeconômica e ecológica, esta última constituída pela posse de terra e pelas relações rural/urbano. Em sua crítica aos estudos de comunidade, argumenta que, se as estruturas de uma cidade ou localidade deveriam ser entendidas partin- 
do das estruturas de gerenciamento econômico das fazendas do entorno, a validade do conceito de estudos de comunidade poderia ser questionada. Aprofundando sua crítica, mostra a inter-relação das localidades. Cita o fato de as cidades serem construídas em terras privadas que, conforme seu crescimento, depois vão sendo desapropriadas pelo governo, criando uma ligação entre si, bem como com as fazendas do entorno. Conforme sua observação de campo, havia ligações econômicas e administrativas entre a cidade e as fazendas, cujo aspecto central seria a posse e o uso da terra. ${ }^{\text {Io }}$

Sua pesquisa na zona do cacau, além do foco nos latifúndios e, portanto, nos grandes produtores, também se voltou para o pequeno produtor e suas estratégias para sobreviver a esse mercado, enfatizando a economia de sobrevivência daqueles que estão à margem do sistema da economia do cacau. Como principal observação acerca dos trabalhadores da zona do cacau, Leeds identifica outro ciclo persistente de exploração da terra e do trabalho. Em sua visão, os pequenos produtores estavam fadados a perder capital diante da desleal correlação de forças com os grandes produtores, bem como a se tornar trabalhadores sem-terra, o que provocaria a tendência ao desaparecimento do pequeno produtor, pois, na melhor das hipóteses, se tornavam trabalhadores a serviço dos grandes produtores. ${ }^{\text {II }}$

Quanto à perspectiva adotada, a expressão total culture pattern, padrão cultural total, foi proposta por Alfred Kroeber (I948), tal como consta em sua obra Anthropology: race, language, culture, psychology, prehistory, para a qual dedica uma seção de um dos capítulos. Segundo Kroeber (I948: 3 I I), um padrão deve ser entendido como conjunto de sistemas ou arranjos internos que daria coerência e sentido a uma determinada cultura, evitando torná-la uma acumulação de partes aleatórias. Desse modo, haveria padrões universais, padrões sistêmicos e padrões totais culturais. Estes últimos designariam padrões culturais que se relacionam com um todo cultural mais abrangente, constituindo os modos como a configuração da cultura italiana, francesa ou inglesa se relaciona com a cultura europeia (Kroeber, I948: 316-317).

O conceito de padrão cultural total orientou a comparação entre as diversas produções agrícolas e extrativas. Em paralelo, outras ideias de Kroeber foram acionadas por Leeds para o entendimento da sociedade brasileira, a exemplo das noções de persistência e mudança cultural. Mudança e persistência cultural seriam ambos processos nos quais interfeririam fatores como invenções, incrementos ou saberes passados de uma cultura a outra (Kroeber, I 948: 344-445). No caso específico da zona do cacau, Leeds relaciona a cultura da região do cacau ao que seria o seu todo cultural, isto é, a cultura brasileira. ${ }^{12}$

O recurso ao conceito de padrão cultural total por Leeds leva em conta possíveis diferenças entre as classes sociais por ele identificadas na estrutura social da região do cacau. No que tange à "classe superior" 13 dos proprietários, Leeds percebe em seus valores uma orientação voltada para a exploração e 
especulação, sendo o consumo e a fruição de tempo livre seus valores principais. Para essa classe, a terra e todo o conjunto de seus negócios seriam vistos somente como meio para conquistar o consumo de bens e hábitos de alto padrão de vida - usar roupas finas, frequentar festas, ter boas casas e tempo livre, buscando distância de tudo que se relacionasse à vida rural. Igualmente importante, e complementar a esses objetivos, seria a exploração e espoliação das riquezas da terra, da capacidade de trabalho dos animais e do homem, sem lhes dar o devido retorno. Em suma, se o principal valor é conquistar riqueza sem trabalho, o incremento técnico e a participação pessoal no trabalho físico seriam desprezíveis. ${ }^{14}$

A "classe baixa", apesar de também ser orientada pela vida urbana e pela satisfação de objetivos imediatos, teria valores específicos diferentes. Desejaria tanto o contato social disponível no lugar quanto as benesses da vida urbana - as oportunidades econômicas, educação e o movimento da cidade. Apesar da ausência de pretensões comerciais, a busca de dinheiro visaria somente ao necessário para obter gratificações marginais e pequenos prazeres. Esse imediatismo não se traduziria no consumo em si, mas no uso da menor coisa disponível no momento para satisfazer qualquer desejo. Assim como a classe alta, também não teria preocupações tecnológicas. ${ }^{15}$

Em ambas as classes sociais, esse valor urbano, para ele, essencialmente pecuniário, teria sido forjado desde a colonização portuguesa. Seria parte central do total culture pattern brasileiro persistente na zona do cacau. ${ }^{16}$ Seria justamente a falta desses valores produtivos, de valores que levassem à preocupação com a inovação e o aprimoramento tecnológico, o empecilho a qualquer melhoria, fosse do cacau, da borracha, do açúcar, entre outros produtos. A ambição de ganhar dinheiro imediato como valor comum a ambas as classes lhes daria essa essência urbana, e também resultaria no desinteresse pelo aumento da produtividade.

Quase 30 anos mais tarde, ao escrever a autobiografia, Leeds faz um balanço desse trabalho. Em suas palavras, a dissertação

era essencialmente uma análise marxista sobre a base e a superestrutura da produção do cacau, ampliada, por um lado, por perspectiva ecológica muito forte e, por outro, por algumas análises inovadoras sobre os sistemas ideológicos das duas principais classes [...] O quadro teórico era moldado pelo conceito kroberiano de padrão cultural total, o qual, quando escrevi, considerei adequado, mas retrospectivamente, considero irrelevante e responsável por confundir duas estruturas muito distintas: social-institucional e cultural (Leeds, 1984: 54).

Ao analisar a tese nos termos em que foi elaborada em finais da década de I950, poderíamos certamente apontar outras influências teóricas distintas da perspectiva marxista, como é o caso da obra de Max Weber (2004) e sua discussão sobre o éthos capitalista em A ética protestante e o espírito do capitalis mo. Além disso, a visão essencialista sobre padrão cultural total e sua aplicação à formação sócio-histórica brasileira impediu análise mais aprofundada dos 
processos sociais em curso na região do cacau, como o autor reconheceria mais tarde. Na perspectiva deste artigo, o mais relevante é destacar a contribuição da tese de Leeds diante de uma preocupação que vem orientando um conjunto de pesquisas na área de pensamento social no Brasil (Botelho, 2009a, 2009b; Lima et al., 20I I). Trata-se de questionar as relações entre rural e urbano em termos de simples dicotomias e problematizar a visão dualista com que muitas vezes elas foram concebidas ao longo de nossa história. Nesse sentido, a obra de Anthony Leeds, envolvendo a tese sobre a zona de cacau e os trabalhos posteriores sobre favelas, barriadas e outros assentamentos, traz relevante contribuição ao apontar para processos, tanto no Brasil como em outras sociedades capitalistas periféricas, nas quais as relações rural/urbano não formaram nem formam passagens unívocas. Conforme trabalhos recentes vêm mostrando, elas formam antes uma relação de interdependência histórica no sentido de que nenhum dos dois princípios de coordenação social isoladamente teria conseguido determinar o processo social na base dos seus valores ou interesses específicos (Botelho, 2009a, 2009b; Lima et al., 20I I). Verifica-se, contudo, na obra de Leeds a primazia concedida ao urbano como esse princípio ordenador, tal como se pode constatar quando o autor afirma em artigo posterior que mesmo os latifúndios tão comuns tanto no Brasil como no Peru são urbanos em sua organização e orientação, ou seja, sistemas essencialmente industriais orientados para os mercados, as atividades e os interesses da cidade (Leeds, 2015 [I970]: I33-I95).

Além das contribuições substantivas da pesquisa, cabe ressaltar o contato com a sociedade brasileira e importantes intelectuais do país na elaboração da tese de doutorado, nunca publicada pelo autor, mas que se constitui em importante referência para o estudo de sua obra e de um capítulo das ciências sociais brasileiras fortemente marcado pelos estudos de comunidade realizados por antropólogos norte-americanos e brasileiros. Muitas questões abordadas na pesquisa sobre produção do cacau acompanhariam seus trabalhos posteriores no Brasil e outros países, a exemplo da análise de posições e valores de classes sociais e do estudo das instituições nacionais, incluindo burocracia, sistema legal, instituições financeiras, entre outras, que modelariam, em seu ponto de vista, as próprias localidades e fortaleceriam a necessidade de superar os limites impostos pelos estudos de comunidade. ${ }^{17}$ Relações estabelecidas com intelectuais brasileiros naquele período, notadamente Thales de Azevedo e Anísio Teixeira, foram fundamentais para as pesquisas que realizou nos anos seguintes, tanto o estudo de carreiras brasileiras como os trabalhos sobre as favelas cariocas. 


\section{O ESTUDO DE CARREIRAS COMO PROPOSTA DE ANÁLISE DA ESTRUTURA SOCIAL BRASILEIRA}

Em I962, Leeds escreveu o que considerava um de seus trabalhos clássicos: o estudo de carreiras, com o objetivo de analisar a sociedade brasileira e construir um modelo teórico referido aos processos de mudança social em curso na América Latina. Em sua autobiografia, percebia esse estudo como uma tentativa de integrar os paradigmas funcional, histórico e evolucionista. A pesquisa sobre carreiras brasileiras ocorreu quando Leeds era chefe do Programa de Desenvolvimento Urbano do Departamento de Relações Sociais da União Pan-amaericana (Panamerican Union - PAU), então um Secretariado da Organização dos Estados Americanos (I96I-I963). Contou com o apoio desse organismo e também da Coordenação de Aperfeiçoamento do Pessoal de Educação Superior (Capes), por intermédio de Anísio Teixeira. O diretor do Departamento de Relações Sociais da PAU era Angel Palerm, antropólogo que havia estudado comunidades no México, o processo de desenvolvimento no sul da Itália e problemas de uso da terra e atividade agrícola em Israel. Leeds o considerava importante influência intelectual, especialmente por seus trabalhos sobre a organização da sociedade urbana (Leeds, I984: 58). No mesmo período foram realizadas visitas para acompanhar o que estava sendo realizado no estudo comparativo de quatro centros de ciências sociais - no Brasil, Uruguai, Argentina e Chile - que integravam o chamado "estudo de quatro cidades". Com apoio da Unesco, os estudos foram realizados no Rio de Janeiro, sob coordenação de Luiz de Aguiar Costa Pinto; ${ }^{18}$ Montevidéu, por Isaac Ganon; Buenos Aires, por Gino Germani com apoio de Jorge Graciarena, Torcuato di Tella, entre outros; e Santiago do Chile, sob responsabilidade de Eduardo Hamuy. O estudo de carreiras foi realizado, assim, no âmbito de uma reflexão mais ampla sobre cidades que, para Leeds, seria complementar ao pensamento sobre a natureza das relações de classe (Leeds, I984: 58).

No início do texto "Carreiras brasileiras e estrutura social: um estudo de caso e um modelo", Anthony Leeds afirma a importância do modelo que desenvolvera para explicar a estrutura de oportunidades sociais na transição de sociedades rurais para sociedades urbanas. Em termos mais precisos referia-se a dois tipos ideais de sociedades organizadas em Estado que caracterizariam as últimas fases conhecidas da evolução cultural e que denominou sociedade estático-agrária e sociedade expansivo-industrial. Lembrado no Brasil pela qualidade e rigor das pesquisas empíricas por ele realizadas é interessante observar a forma como inicia o texto em exame.

A pesquisa que relatarei é interessante para mim não tanto pelos dados em si mesmos, embora eles jamais tenham sido apresentados e tenham um certo fascínio intrínseco, mas antes porque ela é sobretudo uma confirmação detalhada do que eu já conhecia amplamente a partir das reflexões teóricas e algumas observações esparsas. Com efeito, eu já havia descrito meus resultados de campo antes de ter ido a campo (Leeds, 2015 [I962]: 99). 
As observações esparsas a que se refere foram realizadas especialmente por meio de contatos com intelectuais brasileiros, entre eles Thales de Azevedo e Anísio Teixeira. Intrigado com a frequência com que ouvia o termo autodidata, tomou-o como um ponto de indagação acerca da estrutura de oportunidades da sociedade brasileira identificando o fenômeno de múltiplos cargos exercidos por uma única pessoa, referido nas entrevistas que realizou como cabides de emprego. Relacionou os dois fenômenos - a importância dos autodidatas e o cabide - a uma estrutura de oportunidades em expansão, porém não acompanhada do necessário processo de profissionalização para a ocupação das novas posições, fenômeno que estaria acontecendo no Brasil e na América Latina. A estes termos autodidata e cabide, acrescentou o fenômeno das panelinhas, sistema informal de formação de grupos cujas conexões assegurariam posições de poder e prestígio a seus integrantes além de dificultar a presença de novos membros. A pesquisa propriamente dita compreendeu a realização de entrevistas com representantes das elites econômica e intelectual em São Paulo, Rio de Janeiro, Belo Horizonte, Recife e Salvador. No registro das histórias de vida os aspectos mais importantes eram o esboço da carreira passada e presente e a genealogia social, entendida como o mapeamento das ligações pessoais de parentescos, amizades e obrigações mútuas. Os depoimentos foram complementados por pesquisas em jornais que, com alguma frequência, publicavam trajetórias profissionais (Leeds, 2015 [1962]: I08-I09).

Em artigo sobre a influência de Thales de Azevedo nos estudos sobre Brasil realizados por norte-americanos, Anthony Leeds ressalta o papel desse antropólogo tanto no desenvolvimento de suas pesquisas, em particular no estudo sobre carreiras, quanto no conjunto das pesquisas realizadas pelos jovens antropólogos norte-americanos que chegavam à Bahia. ${ }^{19} \mathrm{Em}$ sua opinião, devido a peculiaridades da relação histórica entre nação e região, os cientistas sociais do país seriam predominantemente especialistas dedicados a sociedades regionais ou analistas da sociedade brasileira informados por um viés regional. Thales de Azevedo corresponderia a esse perfil como intelectual essencialmente baiano, adjetivo que exemplificava um padrão identificado por Leeds na formação das ciências sociais no Brasil que, em sua análise, só se modificaria nos anos I960 com o fortalecimento de uma perspectiva efetivamente nacional. Ele mesmo se apresentaria, ao lado de outros cientistas sociais norte-americanos, como baiano por adoção e integrante da família extensa de Thales de Azevedo. Este desempenharia múltiplos papéis, indo muito além das responsabilidades do cargo de diretor da Fundação para o Desenvolvimento da Ciência da Bahia. Atuava como mediador no contato com as elites locais, acolhia estudantes e jovens pesquisadores em sua família, e, no caso de Anthony Leeds, foi responsável por chamar sua atenção para a importância do estudo das elites locais, tendo sido também entrevistado para a pesquisa sobre carreiras, quando compartilhou observações acuradas acerca de fenômenos como "pa- 
nelinhas e igrejinhas". Essa seria a razão para explicar por que o estudo sobre a Bahia se tornou o mais rico e revelador sobre a dinâmica das carreiras (Leeds, I970).

Se a influência de Thales de Azevedo ocorreu nesses diferentes níveis, com peso expressivo das conversas informais, ao lado da entrevista estruturada para fins de pesquisa, a importância de outro intelectual baiano que já havia desempenhado papel-chave no estudo sobre a zona do cacau é afirmada no artigo sobre carreiras brasileiras. Nesse caso, além das conversas informais, os textos de Anísio Teixeira (I953, I957) constituíram referências importantes para a discussão sobre a estrutura social brasileira, especialmente pela explicitação da característica oligárquica de poder no Brasil e da atuação dos grupos de pressão.

Em diálogo com a obra de Anísio Teixeira, Anthony Leeds propõe que a estrutura social brasileira teria a característica de um sistema dual, dividido entre classes sociais, com possibilidade, ainda que de forma desigual, de se beneficiar da estrutura de oportunidades, e um conjunto que denominou massas para quem eram praticamente intransponíveis as barreiras formais e informais existentes.

Em suas palavras:

As massas não são sintomas de "desorganização" ou disfunção ou de uma sociedade "doente". Como a riqueza, o prestígio e o poder de decisão permanecem todos com as classes, que visivelmente não têm nenhum desejo forte de disseminá-los pela população como um todo, mas tiram deles grandes vantagens, o sistema tende a se perpetuar. Além disso, o alto controle exercido sobre as massas tende a forçá-las a procurar nas classes apoio e ajuda, reforçando assim estrutural e ideologicamente o sistema por meio de instituições comumente descritas como "paternalistas" (Leeds \& Leeds, 2015 [I962]: II7).

Essa discussão encontra-se mais desenvolvida na seção do artigo dedicada ao que denominou institucionalização da pobreza, um processo que envolveria não apenas variáveis mais facilmente identificáveis como renda e escolaridade, mas um conjunto de atributos informais, acesso a informações e deixas que garantiriam os mecanismos de exclusão. Daí a importância do estudo de carreira para captar, através de entrevistas e outras fontes como os jornais, o que, dado o grau de informalidade, seria impossível de ser apreendido na literatura, documentos oficiais e estatísticas. Conforme observa:

A institucionalização da pobreza no Brasil compreende uma inflação que, especialmente nos níveis mais baixos, consome praticamente todo aumento salarial concedido, mas que é ao mesmo tempo utilizada pelos ricos para aumentar sua própria renda. Compreende um sistema escolar construído de modo a fomentar o privilégio e expulsar o pobre tão cedo quanto possível; por exemplo, pela dificuldade e custo do atendimento, pela exigência de uniformes que devem ser pagos, pela falta de transporte e frequentemente, quando são alcançados os graus elementares superiores, pela exigência de ensino especial e pago para o prosse- 
guimento. A institucionalização da pobreza também compreende uma extraordinária gama de instituições informais, das quais o controle da transmissão de deixas que discuti é apenas uma (Leeds, 2015 [I962]: II5).

Publicado originalmente em I964, o texto "Brazilian careers and social structure" alcançou grande repercussão na comunidade acadêmica norte-americana. Leeds passou a ser reconhecido como importante analista da estrutura social brasileira, das relações entre as elites e as classes populares, da mobilidade social e das estruturas de poder (Valladares, 2005: I I3). Em sua autobiografia observa que Bertram Hutchinson, diretor de pesquisa do Centro Latino-Americano de Pesquisas em Ciências Sociais, fundado pela Unesco no Rio de Janeiro, havia chamado sua atenção para as potencialidades do estudo dos mecanismos de carreira não apenas entre as elites, mas para a compreensão dos mecanismos utilizados pela classe trabalhadora numa sociedade com expressiva desigualdade. Também observa que sua primeira visita a uma favela carioca teria ocorrido em I96I em companhia de Anísio Teixeira (Leeds, I984: 57).

Em 1965 daria início à pesquisa que o tornou mais conhecido no Brasil, seu estudo sobre favelas, em larga medida com a colaboração de Elizabeth Leeds, no qual formulava crítica ao mito da ruralidade e analisava as estratégias políticas e os recursos mobilizados pelos moradores. Apresentava, à semelhança do que ocorrera na pesquisa sobre a zona do cacau na Bahia, preocupação em estabelecer uma análise de natureza comparativa tanto entre favelas do Rio de Janeiro, onde realizou extenso trabalho de campo, como cotejando a ação política nessas localidades com a dos moradores em assentamentos de outras cidades brasileiras - Curitiba, São Paulo e Salvador - e também latino-americanas, a exemplo das barriadas de Lima e áreas invadidas de Caracas, San Juan (Porto Rico) e Santiago do Chile (Leeds \& Leeds, 20I5: 329-395).

\section{FAVELAS E POBREZA URBANA}

No contexto em que Anthony Leeds realizou suas pesquisas no Brasil, desenvolvimento, mudança dirigida ou provocada e resistências à mudança eram termos correntes no vocabulário dos cientistas sociais (Villas-Bôas, 2006; Clapcs/ Unesco, I960; Maio \& Lima, 2009). A partir de meados da década de I950, identifica-se na literatura acadêmica publicada uma tendência de maior interesse pelo impacto dos processos de industrialização e urbanização então em curso e, em muitos casos, abordaram-se seus problemas na mesma linha das resistências culturais ao desenvolvimento. A pobreza urbana, que começava a ser objeto de interpretações com enfoque das ciências sociais, era com frequência analisada sob esse prisma e foi abordada em toda a América Latina a partir dos pressupostos da teoria da marginalidade e de conceitos como o de cultura da pobreza, proposto por Oscar Lewis (1966).

Leeds questionou essas abordagens, publicando artigos de crítica à tese da cultura da pobreza e ao mito da ruralidade das populações de favelas e ou- 
tras formas de moradia semelhantes nas cidades latino-americanas. A crítica a concepções correntes nas décadas de I950 e ig6o configurou-se como uma das preocupações centrais de sua agenda de pesquisa. Contestava a atitude etnocêntrica de se generalizarem aspectos da urbanização capitalista para o estudo dos fenômenos urbanos em diferentes contextos histórico-culturais.

É no âmbito dessas interpretações mais amplas que podem ser mais adequadamente apreciados seus estudos sobre favelas no Rio de Janeiro e outras formas de moradia popular no Brasil e na América Latina. Ao mesmo tempo, a elaboração de seus argumentos ocorreu com base na pesquisa etnográfica que realizou, no amplo acervo de documentos e registros de observação participante de colaboradores que reuniu. Em suma, trata-se de compreender um processo complexo no qual formação acadêmica prévia, relação com intelectuais e políticos brasileiros, escolhas profissionais e experiência de campo moldaram a contribuição do antropólogo norte-americano.

No momento em que realizou sua pesquisa sobre favelas, a obra de maior abrangência e impacto era o relatório "Aspectos humanos da favela carioca", publicado em O Estado de São Paulo em I960. Tendo sido concebido pelos editores do jornal como uma peça de oposição ao governo Kubitschek e à construção de Brasília, o estudo se tornou a primeira grande contribuição sociológica sobre as favelas, modificando o panorama do pensamento social a elas referido, até então dominado pelas análises médico-higienistas e urbanísticas (Leeds \& Leeds, 20I5; Lima, I989, Mello et al., 20 I 2; Valladares, 2005). Realizada pela Sociedade de Análises Gráficas e Mecanográficas sobre os Complexos Sociais (Sagmacs), teve a orientação do frei dominicano Joseph Louis Lebret, coordenação técnica de José Arthur Rios e supervisão do trabalho de campo por Carlos Alberto de Medina (Rios, 20I2). A experiência desses dois sociólogos em atividades com populações rurais moldava, de modo significativo, o contato com a realidade das favelas, e Medina (I964), por exemplo, chegou a vê-las como um meio funcional na transição de migrantes pobres rurais para a vida nas cidades. Rios se tornaria depois, a convite de Carlos Lacerda, secretário de Serviços Sociais do Estado da Guanabara e foi um dos principais interlocutores de Anthony Leeds em suas pesquisas. Uma análise dos artigos e das referências bibliográficas mobilizadas por este último evidencia que, entre os participantes da pesquisa da Sagmacs, o principal autor com quem dialogam é o arquiteto e urbanista Helio Modesto, cujo trabalho traria evidências para o argumento central dos autores: "as favelas são atravessadas por todas as formas de organização comuns à sociedade inclusiva” (Leeds \& Leeds, 2015: I64).

O estudo da Sagmacs contribuiu para que se consolidasse no pensamento sociológico o binômio pobreza/favela. Conforme observa Maria Isaura Pereira de Queiroz (I978), ele trouxe evidências e argumentos sociológicos para uma associação que já se estabelecia na cultura popular, sobretudo no samba, desde a década de i940. No texto "Favelas urbanas, favelas rurais", a autora de 
Messianismo no Brasil e no mundo observa a mudança nas representações sobre a favela que acompanharam a intensificação da migração para as principais cidades. Estabelece ainda paralelos com o que ocorria no plano da cultura, a exemplo de sambas e outras canções populares: "Por volta de I945, o tema da pobreza se instala: 'lata d’água na cabeça, lá vai Maria, lá vai Maria; pela mão leva a criança...” (Queiroz, I969: 87).

Na mesma direção, Luiz Antonio Machado da Silva (201 2: 53) observou que o elemento unificador do extenso conjunto de dados e observações registradas era a percepção das favelas como territórios da pobreza urbana, associação que, de certo modo se teria naturalizado durante décadas. Tal associação esteve presente, por exemplo, em textos orientados pela teoria da dependência, sobretudo nos que discorreram sobre o conceito de trabalho marginal.

Dois anos depois da publicação do relatório "Aspectos humanos da favela carioca", veio a lume Quarto de despejo: diário de uma favelada, escrito por Carolina Maria de Jesus (I960), no qual pobreza, favela e fome formavam uma tríade indissociável. ${ }^{20} \mathrm{O}$ livro rapidamente se tornou um grande sucesso editorial ao trazer a percepção da autora sobre as condições de vida na favela do Canindé, às margens do rio Tietê, em São Paulo. Segundo Leeds, o livro fora avidamente consumido, mas faltara aos leitores uma perspectiva crítica para lidar com a obra, o que acabava por reforçar o mito da ruralidade dos moradores das favelas. Além disso chama atenção para o fato de as favelas de São Paulo serem menores e mais pobres comparativamente àquelas situadas no Rio de Janeiro (Leeds, 2015 [I970]: I8I).

No campo das expressões artísticas relacionadas aos movimentos de esquerda do período, a favela torna-se também tema corrente, a exemplo da peça Eles não usam black tie, de Gianfrancesco Guarnieri (200I), em que um morro cenográfico do Rio de Janeiro torna-se a arena dos conflitos políticos envolvendo trabalhadores sindicalizados e também conflitos geracionais vividos de forma dramática em face da percepção dos caminhos alternativos em um contexto de consciência sobre a realidade de exclusão social (Pontes \& Miceli, 20I2).

Assim, quando Anthony Leeds retorna ao Brasil, em I965, para o estudo sistemático e extenso nas favelas o imaginário sobre elas alternava-se entre estereótipos negativos e ideias de risco e perigo social à sua percepção como quistos de pobreza e sobrevivência rural na cidade. Conforme ele irá escrever alguns anos depois,

As favelas são concebidas como um problema - como o foram as barriadas de Lima, os arrabaldes de San Juan, os ranchos ou barrios de Caracas, as callampas de Santiago, as villas misérias de Buenos Aires etc. - porque, presume-se, suas populações se constituem, em um dos extremos do mal, de assassinos, ladrões, assaltantes, maconheiros e viciados em drogas; em outro extremo do mal, de comunistas e outros tipos de ameaça em termos políticos e sociais; em um ter- 
ceiro e mais brando extremo, de pobres ignorantes, não educados, mal adaptados, imigrantes rurais caipiras, ou, no melhor dos extremos, de seres humanos razoáveis, mas tristes e pobres, que moram em cabanas, promiscuamente, e criam um câncer social e urbanístico na cidade (Leeds, 20I5 [I974]: I99).

\section{FAVELA, MITO DA RURALIDADE URBANA E ATUAÇÃo POLÍTICA}

A. Leeds experimentou a vida de uma pequena cidade brasileira, a vida da plantação, um pouco da vida camponesa (Leeds, I957), as cliques urbanas (ig64a) e participou da vida da "classe baixa urbana (I966b; com E Leeds e Morocco, I966) e teve longo contato com vários ramos da elite intelectual. [....] Por ter acesso a essas diferentes posições da sociedade, ele conheceu as visões pequeno-burguesa, intelectual de esquerda, intelectual de centro e a visão que os administradores públicos têm das classes baixas, do trabalhador pobre e do favelado (Leeds \& Leeds, 2015: 169).

No artigo "O Brasil e o mito da ruralidade urbana: experiência urbana, trabalho e valores nas 'áreas invadidas' do Rio de Janeiro e de Lima", ${ }^{21}$ Anthony e Elizabeth Leeds argumentam sobre a experiência e os valores urbanos que organizam a vida social das favelas no Rio de Janeiro, estabelecendo comparações com as barriadas de Lima (Leeds \& Leeds, 20 I5 [I970]: I33-I94). Nele se pode constatar o esforço dos autores de, a partir de extensa pesquisa e muitos registros de trajetórias e vivências de moradores, se contrapor às visões dominantes entre as elites e classes médias sobre os pobres urbanos. Tratava-se de conhecer e analisar a visão dos próprios moradores das favelas e a orientação que eles imprimiam a suas atividades cotidianas.

Precisamente com esse objetivo e aproveitando a colaboração que já prestara ao Peace Corps nos Estados Unidos, após ter participado no verão de I 965 do treinamento de 63 voluntários em preparo para atuar no Brasil, Anthony Leeds procurou o diretor do programa no Rio de Janeiro, Joan Marasciullo, que promoveu seu encontro com os voluntários em trabalho nas favelas, sob a proteção do convênio firmado entre o estado da Guanabara e a Aliança para o Progresso, responsável pela entrada do PCV, entre outras agências internacionais e projetos de cooperação técnica, nessas áreas. Tratava-se de experiência recente, pois inicialmente a agência norte-americana tinha priorizado áreas rurais. Tanto nessas áreas como no espaço urbano, o objetivo declarado era levar o conhecimento técnico para a melhoria das condições de vida das populações, sob a égide da noção de desenvolvimento e organização de comunidade (Viana, 20I4; Figueiredo, 2009; Amman, 2009).

Leeds desenvolveu um seminário que constava de um encontro semanal durante mais de um ano com os jovens PCVs e mais tarde incorporou a esta programação cientistas sociais e assistentes sociais brasileiros, além de alguns moradores de favelas. A esses encontros se referem Sieber (I994), Valladares (2005) e Silva (2015), e dele participaram Luiz Antonio Machado da Silva, Licia 
Valladares e Carlos Nelson dos Santos, entre outros cientistas sociais. Esse seminário também é comentado em entrevistas por nós realizadas e na autobiografia de Anthony Leeds (I984: 64). Foram essa rede de pesquisa e a permanente troca de informações e observações sobre a convivência com os moradores que contribuíram significativamente para extensa pesquisa em I 2 localidades nas zonas Norte e Sul da cidade. Durante o período, Anthony Leeds residiu no morro do Tuiuti, onde conheceu Elizabeth Leeds, que se tornaria sua principal colaboradora na pesquisa e com quem se casou em I967. Essa atividade intensa com os PCVs resultou também em um conjunto de comunicações de trabalhos durante $037^{\circ}$ Congresso Internacional de Americanistas, ocorrido em I966 em Mar del Plata ${ }^{22}$ (Leeds, 20 I5 [I970]: I87).

Em linhas gerais, o seminário privilegiava o trabalho empírico e o compartilhamento das observações de campo. Algumas orientações metodológicas e discussões teóricas, entretanto, estavam presentes, conforme se pode verificar pela elaboração de papers para o Congresso Interamericano de Americanis tas. Entre as questões metodológicas, uma das mais relevantes era a proposta de substituir o modelo de estudos de comunidade e adotar a abordagem das favelas como localidades.

O questionamento aos estudos de comunidade esteve presente na obra de Anthony Leeds desde a tese sobre a zona do cacau, mas é no artigo "Poder local em relação com instituições de poder supralocal" que a crítica é formulada de modo mais aprofundado e sistemático (Leeds, 20 I5 [1973]: 63-96). Nesse texto, observa que o principal problema na definição de comunidade é que, ao tomá-la como objeto de estudo, estabelece-se uma unidade socioestrutural de algum tipo para uma localidade. Em geral considera-se a comunidade uma forma de microcosmo que poderia informar sobre processos da sociedade abrangente ou total (Leeds, 2015 [1973]: 67).

Ao discutir o alcance e os limites dos estudos de comunidade para a análise de favelas e outros tipos de assentamentos existentes na América Latina, Anthony Leeds enfatiza a diversidade de relações de sociabilidade e poder forjadas dentro e fora desses espaços, dando ênfase às instituições chamadas de supralocais - o mercado de trabalho, o Estado, a Igreja, os impostos, entre outras (Leeds, 20 I5 [I973]: 67-74). Em sua perspectiva, a vantagem da categoria localidade em relação a comunidade estaria justamente na análise da diversidade de relações dentro e fora dessa localidade, dando maior abrangência e complexidade ao local de estudo, bem como maior foco na interação, e não no isolamento. Ainda que essas ideias já estivessem presentes em sua tese sobre a zona do cacau, foi só após as pesquisas nas favelas que a complexidade das inter-relações pôde adquirir maior peso na contraposição a uma noção de comunidade que não considerasse outros aspectos que lhe poderiam conferir maior complexidade, tais como a identidade do indivíduo e a sensação de pertencimento a um conjunto de valores e de relações, e não só a um espaço 
territorial delimitado. Leeds considerava que o método de estudo de comunidade, originário de sociedades isoladas tradicionalmente analisadas pelos antropólogos foi transferido de forma problemática para as sociedades complexas e seria totalmente inadequado a seu estudo (Leeds, 20 I5 [I973]: 68).

Em sua perspectiva, o recurso ao método no caso das pesquisas em favelas decorreria do equívoco de observá-las como áreas não integradas à cidade. Nos artigos que publicou individualmente e naqueles em coautoria com Elizabeth Leeds, acentua a necessidade de superar a visão etnocêntrica sobre os pobres e, em particular, sobre seus arranjos de vida, que incluíam a moradia em favelas e outros tipos semelhantes de assentamentos. Segundo a perspectiva dos autores, a visão dos moradores como não integrados à vida da cidade decorria de um erro de perspectiva que tomaria como padrão experiências históricas europeias ou norte-americanas. Seria necessário buscar empírica ou teoricamente a compreensão de diferentes formas de integração de favelas, barriadas peruanas ou outras localidades semelhantes na América Latina em seus próprios termos e entendê-las como formas possíveis e viáveis de integração. Afinal, a economia das favelas, o empreendimento, o comércio, bem como a ilegalidade de algumas das práticas, deveriam ser vistos como mais uma estratégia dos moradores para contornar problemas advindos da precariedade de suas condições materiais de vida (Leeds \& Leeds, 2015 [I 970]: I33-242; Leeds, I974).

Nas favelas o atendimento a demandas como o comércio, a melhoria das casas, a urbanização, a organização de redes de luz e água, entre outras, seria o fator crucial para avaliar o seu grau de desenvolvimento, uma vez que o atendimento a essas demandas traria maior volume de capital circulante. ${ }^{23} \mathrm{Da}$ complexidade de demandas e dos mecanismos para atendê-las decorreriam sua diversidade e seu desenvolvimento. De modo semelhante, as favelas são pensadas relacionalmente, isto é, em suas relações com a cidade e com outras favelas, e não de maneira isolada.

Leeds discute o sistema de valores como um aspecto importante para analisar as favelas e atribui grande valor explicativo à vivência urbana, incluindo a antecedente à moradia em grandes centros urbanos, como o Rio de Janeiro. Dentre os diversos componentes urbanos, destaca um sistema de valores orientados para o mercado, para as atividades e para os interesses da cidade. A prática social e a vida dos moradores das favelas seriam orientadas por esse conjunto de valores essencialmente urbanos, tais como a oportunidade de ganhar dinheiro; o mercado de trabalho; a participação política e social em organizações de naturezas diversas, como sindicatos, clubes e associações; a liberdade; o empreendedorismo; a familiaridade com transações comerciais; e o uso de estratégias para obter benefícios próprios. A socialização desses indivíduos nesse conjunto de valores urbanos decorreria de vivências anteriores à migração, favorecendo sua adaptação à vida urbana, sobretudo a experiência ocupacional 
em profissões urbanas (Leeds \& Leeds, 2015 [I970]). Logo, o local de nascimento, como apontavam os adeptos da teoria da ruralidade urbana dos moradores de favelas, se mostrava pouco válido para afirmar tal suposição. Além disso, em muitas favelas residiam terceiras gerações de moradores, ou seja um expressivo número de pessoas sem nenhuma vivência rural. De todo modo, independentemente do fenômeno migratório, são a dinâmica da vida material e o mercado de trabalho que contribuem para a construção de um éthos urbano entre os moradores das favelas. A este aspecto se somam outros de ordem social e cultural, como a liberdade e a politização (Leeds \& Leeds, 20 I5 [I970]: I38).

Ao estabelecer comparações entre as representações da vida na cidade e nas localidades rurais, considerando a experiência de migrantes de inserção recente nas favelas, Anthony \& Elizabeth Leeds reiteram o valor positivo atribuído à primeira. No caso dos migrantes recentes consideram que o fato de os homens não quererem sair da cidade e sua acelerada transformação em indivíduos essencialmente urbanos teriam como explicação a rápida incorporação desses valores urbanos, sobretudo o maior grau de liberdade e o horizonte de expectativas. No caso das mulheres, mais dedicadas às tarefas domésticas, percebem que há um maior desejo de voltar ao local de origem, porém concluem que isto se dá pelo fato de elas não usufruírem das benesses da cidade (Leeds \& Leeds, 20 I5 [I970]: I4I). De todo modo, repete-se a representação das cidades como o lócus de mercado de trabalho, de oportunidades institucionais, de usufruto de benefícios sociais garantidos por instituições de natureza assistencial, e de mais oportunidades de lazer e de vida social mais intensa. Para ambos os gêneros a questão da maior liberdade é valorizada e não se limita ao mercado de trabalho, o que, na percepção dos pesquisadores, se evidencia na linguagem: "No morro eles são livres para usar essa linguagem rica, engraçada, irônica, abusivamente e totalmente incompreensível para os estranhos. Com ela, eles podem gozar o sistema que traz tantas encrencas e privações" (Leeds \& Leeds, 2015 [I970]: I75).

Em seus trabalhos, ganham relevo estruturas de poder externas e internas às favelas e a ação dos moradores, tanto na relação com instituições supralocais como na organização de associações de moradores. Em determinadas localidades ocorreria ademais forte interação entre essas estruturas locais e o universo sindical, à medida que se articulavam formas de resistência a propostas de remoção das favelas em algumas áreas da cidade. Citam como exemplos a atuação do presidente da União dos Trabalhadores Favelados do Borel, membro de diretoria de sindicato, e o esforço para vincular o programa de urbanização de favelas proposto pela Federação das Associações de Favelas do Estado da Guanabara ao sindicato dos trabalhadores metalúrgicos, depois das enchentes de janeiro de 1966 (Leeds \& Leeds, 2015 [I970]: I67).

Também no que se refere a partidos tradicionais e agências de governo, os autores se dedicam a enumerar estratégias dos moradores e a interdepen- 
dência dessas ações, a exemplo da criação de associações de moradores para atender a uma diretriz da Secretaria de Serviços Sociais do Estado da Guanabara durante a gestão de José Arthur Rios. Já havia associações anteriores, mas aquela política de estado foi respondida de forma positiva pelos moradores que a entenderam como uma via para desenvolver ações de urbanização das favelas. ${ }^{24}$ A capacidade de negociação dos moradores e suas relações com as instituições políticas da sociedade inclusiva foi objeto da dissertação de mestrado de Elizabeth Leeds e algumas das conclusões relacionadas a esse tema específico podem ser vistas no texto "Favelas e comunidade política: a continuidade da estrutura de controle social" (Leeds \& Leeds, 2015: 243-326).

Em seu conjunto os textos publicados por Anthony Leeds, individualmente ou em coautoria com Elizabeth Leeds, apresentam evidências empíricas, mas, sobretudo, uma perspectiva inovadora diante de problemas analisados por outros autores em estudos posteriores. É o caso da discussão proposta por Alba Zaluar (I985) em sua análise sobre a teoria social e os pobres nos países de capitalismo periférico. Ao discorrer sobre a crítica ao conceito de trabalhador marginal na teoria da dependência, a autora observa que o processo de acumulação de capital teria sido desvendado, porém continuaria sem o devido esclarecimento o processo de construção de atores políticos entre os trabalhadores urbanos, o que explicaria o lugar negativo ocupado pelas favelas. A autora acentua ainda a importância dos locais de moradia no processo de construção de identidades e organização política pelos trabalhadores em sociedades onde se verificam a instabilidade do emprego e a magnitude do trabalho informal (Zaluar, I985: 35).

É nesta perspectiva, de superar os preconceitos e a visão etnocêntrica sobre os processos de urbanização no Brasil e em outros países da América Latina, que situamos a importância da obra de Anthony Leeds. Argumento semelhante é apresentado por Silva (20I5: 23), que considera a maior qualidade da pesquisa realizada por Leeds "sua decidida ênfase na demonstração empírica do que bem mais tarde veio a ser conceptualizado como 'competência', isto é, o efetivo discernimento contido na orientação que as pessoas imprimem a suas atividades cotidianas". Em sua obra encontramos chaves de leitura e evidências para a crítica à teoria da marginalidade e, ao mesmo tempo, uma perspectiva sobre os moradores das favelas que não os toma como sujeitos passivos vitimados pela pobreza, mas sim como atores políticos que, não obstante a estrutura desigual e a institucionalização de mecanismos de exclusão e pobreza, fazem escolhas, ou seja, manifestam capacidade de agência.

\section{CONCLUSÕES}

A obra de Anthony Leeds teve na busca de uma interpretação abrangente sobre a sociedade brasileira uma de suas principais aspirações. Nela é possível identificar a ambição comum a muitos de seus interlocutores brasileiros: a de construir uma interpretação convincente a respeito dos enigmas do Brasil. E é in- 
teressante que o tenha feito sem caracterizar o país como sociedade única, mas exatamente comparando-o a outros países latino-americanos e identificando semelhanças em muitos de seus processos sociais e políticos.

Muito provavelmente sua tentativa de integrar no mesmo projeto intelectual o estudo da zona do cacau, das carreiras brasileiras e dos trabalhadores urbanos moradores nas favelas, conforme lemos na epígrafe a este artigo, pode parecer a nossa sensibilidade contemporânea uma ilusão biográfica, tal como sugeriu Pierre Bourdieu (I996), chamando atenção para as armadilhas de retrospectivamente conferirmos coerência e previsibilidade a uma trajetória de vida e experiência intelectual, em geral marcadas pelo imponderável e pelo contingente. Escrita em diferentes momentos de sua trajetória profissional e amadurecimento intelectual, a obra traz, todavia, alguns elementos recorrentes, entre eles a consideração do urbano como princípio de ordenação social predominante. É esse primado da experiência urbana e da orientação de valores por um éthos urbano que aproxima seus diferentes estudos realizados no Brasil, especialmente a pesquisa na zona do cacau para sua tese de doutoramento e a pesquisa sobre favelas e outros assentamentos de trabalhadores urbanos.

Tendo influenciado em diferentes graus a formação para a pesquisa de jovens cientistas sociais brasileiros ${ }^{25}$ e norte-americanos, seja no seminário do Peace Corps, seja no curso de antropologia urbana do Museu Nacional, sua obra traz contribuições que nos interpelam a refletir sobre a antropologia e demais ciências sociais e sobre questões substantivas relacionadas à experiência de diferentes atores em face dos processos de mudança social vividos no Brasil durante as décadas de i950 e ig6o.

Este artigo faz parte de uma agenda mais ampla voltada para a análise da presença de antropólogos brasileiros e norte-americanos em estudos de pobreza rural e urbana no Brasil após a Segunda Guerra Mundial, tema ainda insuficientemente analisado pela literatura. ${ }^{26} \mathrm{Em}$ linhas gerais, os estudos mais abrangentes sobre a história das ciências sociais no Brasil privilegiaram sua institucionalização universitária, adotando como marco de origem a criação da Escola Livre de Sociologia e Política, em I 933 e a Universidade de São Paulo, em I934 (Miceli, I989, I995). Entretanto, no campo de estudos sobre pensamento social, tem-se observado a importância de incluir outros parâmetros de abordagem, levando em conta a diversidade de agendas de pesquisa e perspectivas teóricas adotadas (Lima, 20I3; Botelho, 20I3). Faz-se também necessário considerar a importância de grandes projetos de pesquisa apoiados por agências nacionais e internacionais, muitos realizados fora das universidades, como foi o caso dos estudos sobre as favelas nos anos i950 e ig60. Ainda que insuficientemente analisadas, pesquisas realizadas por cientistas sociais brasileiros e norte-americanos naquele contexto participaram do desenvolvimento inicial da sociologia e da antropologia urbanas no Brasil (Silva, 20I5; Valladares, 2005; Velho, 20II). 
É também fonte relevante para ampliar nossa compreensão sobre a diversidade da antropologia norte-americana, que durante os anos I950 e I960 privilegiou o Brasil e outros países na América Latina, escapando tantas vezes, como foi o caso das pesquisas realizadas por Anthony Leeds, das armadilhas de perspectivas etnocêntricas com que, em regra, se analisavam a história e a experiência contemporânea de nossos países. Sua abordagem da mudança social, comparativamente às visões predominantes no período discutido neste trabalho, teve o mérito de não enfatizar resistências culturais e de postular diferentes caminhos para o desenvolvimento, apresentando um contraponto em relação às teorias da modernização. Chamou atenção para os processos próprios às sociedades latino-americanas, que não poderiam reproduzir a trajetória histórica dos países do capitalismo central. Nessa perspectiva, reforça-se a importância do estudo sobre as favelas. Por um lado, nele são retomados alguns temas presentes nos estudos anteriores, como foi o caso da problematização das relações entre rural e urbano na pesquisa sobre o cacau. E também da pesquisa sobre carreiras e visão sobre as elites, especialmente pela identificação das estratégias mobilizadas em uma sociedade desigual marcada por estruturas de poder formais e informais que dificultavam o acesso a posições sociais de maior reconhecimento. A favela não é vista, assim, por suas lacunas, sua falta de "integração", sua "marginalidade", mas pelo seu lugar como espaço de disputas políticas e de conflitos pelo direito à cidade, um espaço urbano cotidianamente transformado por seus moradores em interação com as instituições internas e externas à localidade. Por outro lado, no estudo sobre favelas abre-se uma janela de interpretação por novos ângulos da sociedade inclusiva em que elas se situam, o que se expressa nas estratégias cotidianas, na vida econômica e associativa, nas relações com o que denominou instituições supralocais, mas também na linguagem irônica pela qual as desigualdades sociais e os estigmas são representados.

O estudo das favelas do Rio de Janeiro permitiu um maior refinamento dos argumentos de Leeds sobre a organização social do Brasil. Nessa pesquisa ele pôde superar o viés da abordagem do padrão cultural total, como fizera na pesquisa sobre a zona do cacau, e também a abordagem evolucionista ainda presente no estudo de carreiras. No estudo sobre favelas ganham relevo a historicidade dos processos sociais e as perspectivas de ação política em um cenário de desigualdades. Os resultados indicaram a urbanização, a melhoria das casas, o incentivo à economia por meio da abertura de créditos para empresários e comerciantes dessas localidades, bem como o incentivo aos mecanismos de autoajuda. As pesquisas foram realizadas em um contexto em que ganhava corpo a proposta, logo a seguir implementada, de remoção das favelas e transferência de seus moradores para conjuntos habitacionais de baixo custo e qualidade em áreas distantes de seus locais de trabalho (Valladares, I978; Lima, 20I I; Valladares, 2005; Viana, 20I4). Não se trata, contudo, de pesquisas datadas, 
aplicáveis apenas a uma conjuntura específica, ainda que ao longo dos mais de 50 anos que medeiam o início de seu estudo e a publicação deste artigo novos temas se impuseram à agenda acadêmica e política sobre o lugar das favelas na cidade. O fato de temas como tráfico de drogas e violência urbana dominarem a cena contemporânea nos interpela a procurar caminhos de análise que evitem simplificações na busca de superar a criminalização e os estigmas sobre essas localidades.

Construção mítica sobre o lugar geográfico e social dos pobres na sociedade brasileira e não apenas dos pobres urbanos, como atesta o processo de generalização do próprio uso do termo no início do século XX e sua histórica relação com o emblemático episódio da Guerra de Canudos, ${ }^{27}$ as favelas permanecem como um dos objetos privilegiados de estudos acadêmicos, projetos de governo e representações artísticas. Associada no passado a mitos como o da marginalidade, da desordem, do quisto na cidade; tantas vezes idealizada de forma romântica e analisada segundo alguns dogmas interpretativos, a favela se encontra hoje fortemente relacionada à abordagem da violência urbana (Valladares, 2005; Silva, 2008; Zaluar, I996; Zaluar \& Alvito, I998; Velho \& Alvito, I996; Lima, Misse \& Miranda, 2000). Por mais que sejam variadas as formas de caracterizá-la, ela é uma referência secular na autoimagem das cidades brasileiras e, mais geralmente, na das cidades do capitalismo periférico. Nesse sentido, mitos e realidades se confundem na produção e reprodução da forma social do urbano (Lima et al., 2009). Ao mesmo tempo em que importa questionar o uso homogeneizador do termo e apontar o caráter heterogêneo e as transformações por que passaram nas últimas décadas esses espaços, incluindo o processo de mobilidade social que vem caracterizando muitos deles, não deixa de ser instigante pensar na retomada de "soluções" e discursos que parecem ecos do que se proclamava nas décadas de i960 e I970, período no qual a remoção foi apontada como principal alternativa nos planos de governo e na mídia. É também significativo o fato de, a partir da década de I990, o tema favela ter aumentado sua visibilidade na produção acadêmica em estreita relação com os estudos sobre violência urbana (Valladares, 2005).

No plano da sociabilidade de seus moradores, os trabalhos de Luiz Antonio Machado da Silva vêm propondo o conceito de sociabilidade violenta, em um esforço de contribuir para análise do modo como são experimentadas as transformações nas relações sociais e de poder que marcam o cotidiano nas cidades brasileiras contemporâneas, cujas populações participam da ordem institucional-legal e também de um padrão de sociabilidade caracterizado pela transformação da força no princípio de coordenação das ações sociais (Silva, I997; 2004 e 2008). Tal padrão afetaria mais profundamente as populações que residem em favelas e outras formas de moradia popular e teria como efeitos mais relevantes a perda de legitimidade dos moradores e de suas associações de representação de interesses nas arenas políticas; a incomunicabilidade e o 
esgarçamento das relações de vizinhança (Silva, 2008). Considerar as mudanças nas formas de sociabilidade nas populações urbanas e seus impactos nas favelas em perspectiva histórica constitui importante desafio. Desse modo, realizar investigações que retomem criticamente as etnografias realizadas nas favelas durante a década de i 960 pode iluminar aspectos relacionados à sociabilidade entre os moradores; ao exame das diferentes redes sociais de que participavam e aos significados atribuídos a sua experiência social.

E aqui se encontram uma das principais contribuições e a atualidade do pensamento de Anthony Leeds, ao propor uma abordagem que considera a favela parte da cidade e seus moradores não vítimas passivas, mas sujeitos capazes de dar sentido a suas decisões cotidianas e participar de todas as dimensões da cidadania. Em tempos em que o binômio pobreza urbana/favela parece ter sido substituído por violência/favela e pela metáfora da guerra a justificar formas discriminatórias em relação a seus moradores, seja em sua face mais dramática, como é o caso da política de segurança, seja em outras políticas públicas, como as de educação, saúde e cultura, a leitura da obra de Anthony Leeds é um convite a se pensar em outras bases o direito à cidade.

Recebido em I8/7/20I8 | Aceito em I I/9/20I8

Nísia Trindade Lima é socióloga, mestre em ciência política e doutora em sociologia pelo Iuperj, atual Iesp/Uerj. É pesquisadora da Casa de Oswaldo Cruz/Fiocruz, docente do Programa de PósGraduação em História das Ciências e da Saúde, presidente eleita da Fiocruz e professora colaboradora do Programa de Pós-

Graduação em Sociologia do Iesp/Uerj. Dentre suas publicações, destacam-se Um sertão chamado Brasil (2 ed., 2013) e, em colaboração com Gilberto Hochman, Médicos intérpretes do Brasil (20I5). Coordena, com André Botelho, a Biblioteca Virtual do Pensamento Social (bvps.fiocruz.br).

Rachel de Almeida Viana é socióloga, mestre e doutoranda em História das Ciências pelo PPGHCS da COC/Fiocruz. É autora da dissertação Antropologia, desenvolvimento e favelas: a atuação de Anthony Leeds na década de ig6o. 


\section{NOTAS}

I Agência governamental norte-americana criada durante o governo de John Kennedy com o objetivo de melhorar a imagem dos EUA, os Peace Corps utilizavam a ação de voluntários, em geral jovens universitários, em programas assistenciais na América Latina nos campos da educação, saúde e extensão rural. Para o Brasil, vieram voluntários de I96I a I98I e, entre eles, Elizabeth Leeds que, além de atuar em programa de saúde em favelas cariocas, realizou pesquisas sobre essas localidades, incluindo a que resultou em sua tese de doutoramento. Para uma visão geral sobre o Peace Corps, ver Hoffman (I998). Sobre a atuação do Peace Corps no Brasil ver Valladares (2002 e 2005) e Azevedo (2007).

2 O livro resultou de uma iniciativa de Gilberto Velho, que havia estreitado a relação com Anthony Leeds no período em que este foi professor do primeiro curso de antropologia urbana no Programa de Antropologia Social do $\mathrm{Mu}$ seu Nacional Velho (20II). Recorremos neste artigo à segunda edição, organizada por Elizabeth Leeds e Nísia Trindade Lima e publicada em 2015 (Leeds \& Leeds, 2015).

3 Originalmente, esse trabalho foi apresentado em 16/ıo/ı962 para a Sociedade Antropológica de Washington, DC. E foi publicado pela primeira vez em I964, na revista American Anthropologist, 66/6, p. I32I-I347.

4 Para uma discussão sobre a teoria da modernização e a crítica feita a essa abordagem por Maria Sylvia de Carvalho Franco ver Botelho (2013). Para o autor: "a sociologia política de Maria Sylvia de Carvalho Franco pode ser entendida como um tipo de contraposição crítica persistente à ideia, presente nas teorias da modernização, de que as inovações modernizadoras funcionariam como variáveis sistêmicas interligadas e intercambiáveis de modo (relativamente) independente dos seus contextos históricos. O que recoloca em discussão, de maneira pungente, a relação entre teoria e história na sociologia" (Botelho, 2013: 366).

5 Programa de cooperação técnica internacional entre os Estados Unidos e os países latino-americanos proposto pelo presidente norte-americano Harry Truman em seu discurso de posse, em janeiro de I949. Recebeu esse nome por ser o quarto ponto do discurso presidencial. 
6 Research and problems in the cacao zone. Pg. I. NAA/Anthony Leeds Papers/ series 2, subseries cacao zone, box I7, relatories.

7 Há uma cópia microfilmada da tese na Universidade de Ann-Harbor e outra cópia encadernada de 679 páginas (três volumes), sendo parte de uma segunda remessa de documentos escritos do acervo pessoal do antropólogo doados por Elizabeth Leeds, recentemente depositada no Departamento de Arquivo e Documentação da Casa de Oswaldo Cruz, não estando ainda disponível para consulta. Além dessas cópias, encontram-se no National Anthropological Archives do Smithsonian Institute dossiês com uma versão de sua tese, organizados fora da ordenação numérica das páginas. NAA/Anthony Leeds Papers/ series 2 subseries cacao zone.

8 Research and problems in the cacao zone. NAA/Anthony Leeds Papers/ series 2, subseries cacao zone, box I7, relatories. Economic cycles in Brazil: the persistence of a total culture pattern: Cacao Zone and other cases. Draft. NAA/Anthony Leeds Papers/series 2 subseries cacao zone, box I4, dissertation draft I of 4 .

9 Research and problems in the cacao zone. NAA/Anthony Leeds Papers/ series 2, subseries cacao zone, box I7, relatories.

Io Research and problems in the cacao zone. NAA/Anthony Leeds Papers/ series 2, subseries cacao zone, box I7, relatories.

I I Research and problems in the cacao zone. NAA/Anthony Leeds Papers/ series 2, subseries cacao zone, box I7, relatories.

I2 Economic cycles in Brazil: the persistence of a total culture pattern: Cacao Zone and other cases. NAA/Anthony Leeds Papers/series 2 subseries cacao zone, box I4, dissertation draft I of 4 .

I3 A expressão, do mesmo modo que classe baixa, é utilizada no rascunho da tese, mas modificado na versão final.

I4 Economic cycles in Brazil: the persistence of a total culture pattern: Cacao Zone and other cases. NAA/Anthony Leeds Papers/series 2 subseries cacao zone, box I4, dissertation draft I of 4 .

I5 Economic cycles in Brazil: the persistence of a total culture pattern: Cacao Zone and other cases. NAA/Anthony Leeds Papers/series 2 subseries cacao zone, box I4, dissertation draft I of 4 . 
I6 Economic cycles in Brazil: the persistence of a total culture pattern: Cacao Zone and other cases. NAA/Anthony Leeds Papers/series 2 subseries cacao zone, box I4, dissertation draft I of 4 .

I7 Sobre estudos de comunidade e a institucionalização das ciências sociais no Brasil, ver Oliveira \& Maio, 20II. Segundo os autores: "Ao abordarmos a produção de EC no Brasil, observamos que, nas controvérsias em torno desses estudos, entre os anos I940 e I960, a visão crítica de alguns cientistas sociais prevaleceu sobre as considerações favoráveis que também lhe foram feitas. Não obstante a força das críticas, a realização de EC permitiu o avanço do processo de institucionalização das ciências sociais no Brasil, com o treinamento de uma geração de pesquisadores mediante investigação de campo. Também por meio desses estudos, as ciências sociais revelaram importantes questões econômicas, políticas e sociais do contexto histórico do período, visto que estiveram voltadas para comunidades rurais em franco processo de mudança social, numa conjuntura marcada pela transformação de um país essencialmente rural e agrário em país urbano e industrial. O interesse em investigar os EC devese ao objetivo de compreender as relações entre sociedade e produção intelectual no contexto da era do desenvolvimento.

I8 Sobre Costa Pinto, consultar Botelho, 2009a, Maio \& Villas-Bôas, I999.

I9 Sobre Thales de Azevedo consultar Maio, I997, Correa, 2015 e Consorte, 1996.

20 Há uma discussão na literatura sobre a autoria de Carolina e o papel do jornalista Audálio Dantas que não caberia explorar neste artigo. Para uma discussão sobre trajetória de Carolina e os paradoxos de seu sucesso e recepção, ver Silva (2013).

2I "Publicado originalmente em City and country in the third world, I970. Os dados deste trabalho para o Rio de Janeiro provêm de oito meses de trabalho de campo nas favelas e, para Lima, de artigos de William Mangin e John Turner e extensas conversas com os dois, duas longas entrevistas com José Matos Mar, várias visitas às barriadas e dois meses de pesquisa de Elizabeth Leeds para Turner 
lidando com comparações entre as duas cidades" (Leeds, 2015 [1970]: I35).

22 Entre os trabalhos apresentados no simpósio de antropologia urbana no $37^{\circ}$ Congresso Internacional de Americanistas, em setembro de 1966, estão: Anthony Leeds e Elizabeth Leeds, "The political complementarity of favelas with the external political structure of Rio de Janeiro"; Elizabeth Leeds, "Political complementary of favelas with larger society of Rio de Janeiro"; David Morocco, "Carnaval groups-mainteiners and itensifiers of the favela phenomenon in Rio de Janeiro"; Charles O'Neil, "Problems of urbanization in Rio favelas"; Nancy Smith, "Eviction! Land, tenure, law, power and the favela"; James Wygand, "Water networks: their technology and sociology in Rio favelas"; Judith Hoenack, "Resources and sources: marketing, supply and the social ties in Rio Favelas".

23 Quanto vale uma favela. BR RJ COC LE DP DR 02.

24 Para uma discussão sobre as diferentes experiências associativas entre moradores de favelas e a presença do Partido Comunista na década de I950, ver Lima (I989).

25 Entre eles estão Gilberto Velho, Yvonne Maggie, Luiz Antonio Machado da Silva e Carlos Nelson Ferreira dos Santos, Licia Valladares (Lima, 20II; Velho, 20II).

26 A presença de cientistas sociais norte-americanos tem sido lembrada nas análises sobre a Escola Livre de Sociologia e Política (Limongi, I989; Valladares, 2005). Permanecem, contudo, pouco estudadas iniciativas que ocorreram fora da universidade, como foi o caso das pesquisas realizadas, na década de I950, pelo Serviço de Educação Rural, pelo Serviço Especial de Saúde Pública, e pelo Serviço de Proteção ao Índio. Sobre a cooperação de cientistas sociais norte-americanos e brasileiros nestes dois últimos organismos, ver Maio \& Lima, 2009; Lima \& Maio, 2010; Figueiredo, 2009 e Brito \& Lima, 2013.

27 Conforme as pesquisas de Maurício Abreu (I994), apenas na segunda década do século XX a categoria favela tornou-se um substantivo genérico para designar determinado tipo de aglomerado urbano. Como observa Licia Valladares (2005), tal fenômeno foi uma decorrência do imaginário em torno do Morro da Favela para onde se 
dirigiram soldados que haviam combatido na Guerra de Canudos e, principalmente, da força simbólica do livro Os sertões no pensamento social e político brasileiro (Valladares, 2005: 26; Lima, I999).

\section{REFERÊNCIAS BIBLIOGRÁFICAS}

Abreu, Maurício de Almeida. (I994). Reconstruindo uma história esquecida: origem e expansão inicial das favelas do Rio. Espaço e debates, São Paulo, I4/37, p.34-46.

Amman, Safira Bezerra. (2009). Ideologia do desenvolvimento de comunidade no Brasil. São Paulo: Cortez Editora, I I ed. Azevedo, Cecília. (2007). Em nome da América: os corpos da paz no Brasil. São Paulo: Alameda Casa Editorial.

Botelho, André. (2013). Teoria e história na sociologia brasileira: a crítica de Maria Sylvia de Carvalho Franco. Lua Nova, 90, p. 33I-366.

Botelho, André. (2009a). Passagens para o Estado-nação: a tese de Costa Pinto. Lua Nova, 77, p. I47-I77.

Botelho, André. (2009b). Universal e particular na sociologia brasileira da mudança social (resenha). Sociologias, 2I, p. 366-377.

Bourdieu, Pierre. (1996). A ilusão biográfica. In: Ferreira, Marieta M. \& Amado, Janaína (orgs.). Usos e abusos da história oral. Rio de Janeiro: Editora FGV.

Brito, Carolina Arouca Gomes de \& Lima, Nísia Trindade. (2013). Antropologia e medicina: assistência à saúde no Serviço de Proteção aos Índios (1942-I956). Boletim do Museu Paraense Emílio Goeldi: Ciênc. Humanas, Belém, 8/I, p. 95-II 2.

Clapcs/Unesco. (1960). Seminário Internacional Resistências à mudança - fatores que impedem ou dificultam o desenvolvimento, Anais (publicação n. Io).

Consorte, Josildeth Gomes. (I999). "Lembrando Costa Pinto: memória das ciências sociais no Brasil". In: Maio, Marcos Chor e Villas Bôas, Gláucia (org.) Ideais de modernidade e sociologia no Brasil. Ensaios sobre Luiz de Aguiar Costa Pinto. Porto Alegre: Ed. UFRGS, p. 39-48. 
Consorte, Josildeth Gomes. (I996). Thales de Azevedo: desaparece o último dos pioneiros dos antropólogos brasileiros de formação médica. Depoimento de Thales de Azevedo a Marcos Chor Maio. História, Ciências, Saúde Manguinhos, Rio de Janeiro, 3/I, p.I33-I7I.

Consorte, Josildeth Gomes \& Pereira, João Baptista Borges. (20Io). Entrevista a Lílian de Lucca Torres. Ponto Urbe. São Paulo, 6.

Corrêa, Marisa. (20I5). Thales de Azevedo: o pequeno lorde. In: Hochman, Gilberto \& Lima, Nísia V. Trindade (orgs.). (2015). Médicos intérpretes do Brasil. São Paulo: Hucitec, p. 4I0-426.

Figueiredo, Regina Erica Domingues. (2009). Histórias de uma antropologia da "boa vizinhança": um estudo sobre o papel dos antropólogos nos programas interamericanos de assistência técnica e saúde no Brasil e no México (I942-I960). Tese de Doutorado. PPGAS/Universidade Estadual de Campinas.

Guarnieri, Gianfrancesco. (200I). Eles não usam black tie. I 2 ed. Rio de Janeiro: Civilização Brasileira.

Hoffman, Elizabeth C. (1998). All you need is love: the Peace corps and the spirit of the I960's. Cambridge: Harvard University Press.

Jesus, Carolina Maria de. (I960). Quarto de despejo: diário de uma favelada. Rio de Janeiro: Francisco Alves.

Kroeber, Alfred L. (I948). Anthropology: race, language, culture, psychology, prehistory. New York: Harcourt, Brace and Company.

Leeds, Anthony. (20I5) [1974]. Tipos de moradia, arranjos de vida, proletarização e a estrutura social. In: Leeds, Anthony \& Leeds, Elizabeth. A sociologia do Brasil urbano. 2 ed. organizada por Elizabeth Leeds \& Nísia Trindade Lima. Rio de Janeiro: Editora Fiocruz.

Leeds, Anthony. (20I5) [1973]. Poder local em relação com instituições de poder supralocal. In: Leeds, Anthony \& Leeds, Elizabeth. A sociologia do Brasil urbano. 2 ed. organizada por Elizabeth Leeds \& Nísia Trindade Lima. Rio de Janeiro: Editora Fiocruz.

Leeds, Anthony. (2015) [I962]. Carreiras brasileiras e estrutura social. Um estudo de caso e um modelo. In: Leeds, 
Anthony \& Leeds, Elizabeth. A sociologia do Brasil urbano. 2 ed. organizada por Elizabeth Leeds \& Nísia Trindade Lima. Rio de Janeiro: Ed. Fiocruz.

Leeds, Anthony. (1994). Cities, classes and the social order. Edited by Roger Sanjek. New York: Cornell University Press.

Leeds, Anthony. (1984). Through self ethnography to human nature. Continuous diversity as escape from categories to unity. Autobiografia não publicada, originalmente destinada à série Being an anthropologist. NAA/AL papers/series 6, sbs biographcial materials, box 33, draft autobiography.

Leeds, Anthony. (1970). Thales de Azevedo's influence on Brazilian's studies by North-Americans: a personal note. Universitas, Salvador, 6-7.

Leeds, Anthony. (1964). Brazilian careers and social structure: an evolutionary model and case history. American Anthropologist, 66/6, p. I32I-I347.

Leeds, Anthony. (1957). Economic cycles in Brazil: the persistence of a total cutlure pattern: cacao and other cases. Tese de Doutorado. Columbia University.

Leeds, Anthony \& Leeds, Elizabeth. (2015). A sociologia do Brasil urbano. 2 ed. organizada por Elizabeth Leeds \& Nísia Trindade Lima. Rio de Janeiro: Editora Fiocruz.

Leeds, Anthony \& Leeds, Elizabeth (2015) [1978]. Favelas e comunidade política: a continuidade da estrutura de controle social. In: Leeds, Anthony \& Leeds, Elizabeth. A sociologia do Brasil urbano. 2 ed. organizada por Elizabeth Leeds \& Nísia Trindade Lima. Rio de Janeiro: Editora Fiocruz.

Leeds, Anthony \& Leeds, Elizabeth. (20I5) [I970]. O Brasil e o mito da ruralidade urbana. In: Leeds, Anthony \& Leeds, Elizabeth. A sociologia do Brasil urbano. 2 ed. organizada por Elizabeth Leeds \& Nísia Trindade Lima. Rio de Janeiro: Editora Fiocruz.

Lewis, Oscar. (1966). La vida: a Puerto Rican family in the culture of poverty. New York: Random House.

Lima, Nísia Trindade. (20I3). Um sertão chamado Brasil. 2 ed. revista e ampliada. São Paulo: Hucitec. 
Lima, Nísia. Trindade. (20I I). História das favelas e da sociologia do Brasil urbano: contribuições a seu estudo a partir da trajetória de Anthony Leeds. Relatório final do projeto apresentado à Faperj na modalidade APQı. Rio de Janeiro.

Lima, Nísia Trindade. (1999). Um sertão chamado Brasil: intelectuais e representação geográfica da identidade nacional. Rio de Janeiro: Revan/Iuperj/Ucam.

Lima, Nísia V. Trindade. (I989). O movimento de favelados do Rio de Janeiro - políticas de estado e lutas sociais. Dissertação de Mestrado em Ciência Política. Instituto Universitário de Pesquisas do Rio de Janeiro.

Lima, Nísia Trindade et al. (coord.). (2009). Sob o signo do desenvolvimento: ciências sociais, educação sanitária e alimentação (1945-I964). Projeto Edital Cientista do Nosso Estado, Faperj.

Lima, Nísia Trindade \& Maio, Marcos Chor. (2010). Ciências sociais e educação sanitária: a perspectiva do Serviço Especial de Saúde Pública na década de I950. História, Ciências, Saúde - Manguinhos, I7/2, p. 5II-526.

Lima, Nísia Trindade et al. (coord). (20I I). Cartografias do rural no pensamento social brasileiro. Projeto Edital Humanidades, Faperj.

Lima, Roberto Kant; Misse, Michel; Miranda, Ana Paula M. (2000). Violência, criminalidade, segurança pública e justiça criminal no Brasil: uma bibliografia. Boletim Informativo e Bibliográfico de Ciências Sociais - BIB, 50.

Limongi, Fernando. (1989). A Escola Livre de Sociologia e Política em São Paulo. In: Miceli, Sérgio (org.). História das Ciências Sociais no Brasil, I. São Paulo: Idesp/Fapesp.

Maio, Marcos Chor. (1997). A história do projeto Unesco: estudos raciais e ciências sociais no Brasil. Tese de Doutorado em Ciência Política. Instituto Universitário de Pesquisas do Rio de Janeiro.

Maio, Marcos Chor \& Lima, Nísia V. Trindade. (2009). Tradutores, intérpretes ou promotores de mudança? Cientistas sociais, educação sanitária rural e resistências culturais (I940-I960). Sociedade e Estado, Brasília, 24, p. 529-56I.

Maio, Marcos Chor \& Villas-Bôas, Glaucia (orgs.). (I999). Ideais de modernidade e sociologia no Brasil. Ensaios sobre Luiz de Aguiar Costa Pinto. Porto Alegre: Ed. UFRGS. 
Medina, Carlos Alberto de. (I964). A favela e o demagogo. São Paulo: Livraria Martins Editora.

Mello, Marco Antônio da Silva et al. (orgs.). (2012). Favelas cariocas. ontem e hoje. Rio de Janeiro: Garamond.

Miceli, Sergio (org.). (I995). História das Ciências Sociais no Brasil, 2. São Paulo: Idesp/Fapesp.

Miceli, Sergio (org.). (I989). História das Ciências Sociais no Brasil, I. São Paulo: Idesp/Fapesp.

Oliveira, Nemuel da Silva \& Maio, Marcos Chor. (20II). Estudos de Comunidade e ciências sociais no Brasil. Revista Sociedade e Estado, 26/3, p. 521-550.

Pontes, Heloisa \& Miceli, Sergio. (2012). Memória e utopia na cena teatral. Sociologia \& Antropologia, Rio de Janeiro, 2/4, p. 24I-264.

Queiroz, Maria Izaura Pereira de. (I969). Favelas urbanas, favelas rurais. Revista do Instituto de Estudos Brasileiros, São Paulo, 7.

Rios, José Arthur. (2012). Aspectos humanos das favelas cariocas - 50 anos: uma avaliação. In: Mello, Marco Antônio da Silva et al. (orgs.). Favelas cariocas. ontem e hoje. Rio de Janeiro: Garamond, p. 35-50.

Sanjek, Roger. (1994). The holistic anthropology of Anthony Leeds. In: Leeds, Anthony. Cities, classes and the social order. Edited by Roger Sanjek. New York: Cornell University Press, p. 27-45.

Sieber, Timothy. (1994). The life of Anthony Leeds: unity in diversity. In: Leeds, Anthony. Cities, classes and the social order. Edited by Roger Sanjek. New York: Cornell University Press, p. 3-26.

Silva, Luiz Antonio Machado da. (2015). Anthony Leeds visto por um filhote ligeiramente rebelde. In: Leeds, Anthony \& Leeds, Elizabeth. 2 ed. organizada por Nísia Trindade Lima \& Elizabeth Leeds. A sociologia do Brasil urbano. Rio de Janeiro: Editora Fiocruz.

Silva, Luiz Antonio Machado da. (2012). A partir do relatório da Sagmacs: as favelas, ontem e hoje. In: Mello, Marco Antônio da Silva et al. (orgs.). Favelas cariocas. ontem e hoje. Rio de Janeiro: Garamond, p. 5I-64.

Silva, Luiz Antonio Machado da. (2008). Violência urbana, sociabilidade violenta e agenda pública. In: Silva, Luiz 
Antonio Machado da (orgs.). Vida sob cerco: violência e rotina nas favelas do Rio de Janeiro. Rio de Janeiro: Nova Fronteira/Faperj, p. 35-46.

Silva, Luiz Antonio Machado da. (2004). Sociabilidade violenta: uma dificuldade a mais para a ação coletiva nas favelas. In: Silva, Luiz Antonio Machado da et al. (orgs.). Rio: a democracia vista de baixo. Rio de Janeiro: Ibase.

Silva, Luiz Antonio Machado da. (1997). Criminalidade violenta e ordem pública: nota metodológica. Trabalho apresentado no VIII Congresso da Sociedade Brasileira de Sociologia. Brasília, mimeo.

Silva, Mário Augusto Medeiros da. (2013). A descoberta do insólito. Literatura negra e literatura periférica no Brasil (I9602000). Rio de Janeiro: Aeroplano.

Teixeira, Anísio. (1957). Educação não é privilégio. São Paulo: Editora Nacional.

Teixeira, Anísio. (I953). Educação para a democracia. 2 ed. São Paulo: Editora Nacional.

Valladares, Licia do Prado. (2005). A invenção da favela: do mito de origem à favela.com. Rio de Janeiro: Editora FGV.

Valladares, Licia do Prado. (2002). Le langage de la coopération internacionale. Peace Corps et ONGs dans les favelas à Rio de Janeiro. In: Cefai, Daniel \& Joseph, Isaac (orgs.). L'heritage du pragmatisme; conflits d'urbanité et épreuves de civisme. Paris: Le Moulin du Château/Editions de l'Aube, p. I75-I9I.

Valladares, Licia do Prado. (1978). Favela, política e conjunto residencial. Dados, Rio de Janeiro, I2, p 74-85.

Velho, Gilberto. (20II). Antropologia urbana: interdisplinaridade e fronteiras do conhecimento. Mana, Rio de Janeiro, I7/I, p. I6I-I85.

Velho, Gilberto \& Alvito, Marcos (orgs.). (I996). Cidadania e violência. Rio de Janeiro: UFRJ/FGV.

Viana, Rachel de Almeida. (20I4). Antropologia, desenvolvimento e favelas: a atuação de Anthony Leeds na década de I96o. Dissertação de Mestrado. PPGHCS/Casa de Oswaldo Cruz/ Fiocruz.

Villas Bôas, Glaucia. (2006). Mudança provocada: passado e futuro no pensamento sociológico brasileiro. Rio de Janeiro: Editora FGV. 
804

Wagley, Charles; Azevedo, Thales de \& Pinto, Luiz de Aguiar da Costa. (I950). Uma pesquisa sobre a vida social no Estado da Bahia. Salvador: Museu do Estado da Bahia (Publicações do Museu do Estado da Bahia, II).

Weber, Max. (2004). A ética protestante e o espírito do capitalismo. São Paulo: Martin Claret.

Zaluar, Alba. (1996). A globalização do crime e os limites da explicação local. In: Velho, Gilberto \& Alvito, Marcos (orgs.). Cidadania e violência. Rio de Janeiro: UFRJ/FGV, p. 48-68.

Zaluar, Alba. (1985). A máquina e a revolta. As organizações populares e o significado da pobreza. São Paulo: Brasiliense. Zaluar, Alba \& Alvito, Marcos (orgs.). (I998). Um século de favela. Rio de Janeiro: Editora FGV. 
Palavras-chave

Anthony Leeds; estudos urbanos; Projeto Bahia-Columbia; história da antropologia; favelas.

\section{ENTRE LATIFÚNDIOS E FAVELAS: O BRASIL URBANO NO PENSAMENTO DE ANTHONY LEEDS}

\section{Resumo}

Neste artigo pretendemos analisar a contribuição de Anthony Leeds em seus trabalhos realizados no Brasil. Estabelecemos, com esse propósito, elementos de comparação entre a tese de doutoramento sobre a zona do cacau, a pesquisa sobre carreiras brasileiras e a análise sobre favelas. $\mathrm{O}$ estudo de sua obra permite ampliar a compreensão sobre as ciências sociais produzidas por antropólogos norte-americanos sobre o Brasil e a América Latina durante as décadas de I950 a I970, destacando perspectivas críticas ao pensamento hegemônico norte-americano orientado por teorias como a da modernização. Argumentamos que o estudo das favelas do Rio de Janeiro permitiu um maior refinamento dos argumentos de Leeds sobre a organização social no Brasil. Mais que localidades onde residiam pobres urbanos, elas foram vistas por ele como estruturas dinâmicas de circulação de pessoas e capitais, expressando as estratégias dos trabalhadores urbanos para lidar com as contradições de uma sociedade que vivia um acelerado processo de urbanização.

\section{BETWEEN ESTATES AND FAVELAS: URBAN BRAZIL IN THE THOUGHT OF ANTHONY LEEDS}

Keywords

Anthony Leeds;

urban studies;

Bahia-Columbia Project; History of Anthropology;

favelas.

\section{Abstract}

In this article we analyse the contribution by Anthony Leeds through is research undertaken in Brazil. This aim in mind, we set out the elements for a comparison between his doctoral thesis on the cacao zone, his research on Brazilian careers and his analysis of favelas. The study of his work enables us to broaden our understanding of the social science produced by US anthropologists on Brazil and Latin America from the I950s to the I970s, highlighting perspectives critical of the US hegemonic thought geared towards theories like modernization. We argue that the study of Rio de Janeiro's favelas allowed a greater refinement of Leeds's arguments on social organization in Brazil. More than localities where the urban poor resided, they were seen by him as dynamic structures involving an intense circulation of people and capital, expressing the strategies developed by urban workers to deal with the contradictions of a society undergoing a rapid process of urbanization. 